\title{
Indications and Results of Thyroidectomies in Northern Senegal
}

\author{
Diatou Gueye Dia1, Hady Tall², Jacques Noel Tendeng², Amadou Diop Dia1, \\ Ibrahima Louis Martin Dieng'2, Ibrahima Konaté ${ }^{1}$ \\ ${ }^{1}$ Faculty of Health Sciences, Université Gaston Berger, Saint-Louis, Senegal \\ ${ }^{2}$ Régional Hospital of Saint-Louis, Saint-Louis, Senegal \\ Email:diadiami@yahoo.fr
}

How to cite this paper: Dia, D.G., Tall, H., Tendeng, J.N., Dia, A.D., Dieng, I.L.M. and Konaté, I. (2018) Indications and Results of Thyroidectomies in Northern Senegal. Open Journal of Internal Medicine, 8, 18-23. https://doi.org/10.4236/ojim.2018.81003

Received: November 28, 2017

Accepted: January 20, 2018

Published: January 23, 2018

Copyright $\odot 2018$ by authors and Scientific Research Publishing Inc. This work is licensed under the Creative Commons Attribution International License (CC BY 4.0).

http://creativecommons.org/licenses/by/4.0/ (c) (i) Open Access

\begin{abstract}
Goiters account for a very high prevalence disease. In Senegal, surgery is a very important part of the management. Our aim is to determine indications and results of thyroidectomies at the regional hospital of St. Louis. Patient and Method: We conducted a descriptive retrospective study over a period of 6 years on 81 records. All patients who underwent thyroidectomy during the study period were included. Computer software EPI INFO and Excel were used for collection and processing of data. Results: The average age of our patients was 40 years with a sex ratio at 0.05 . The determination of TSH found $88.9 \%$ in euthyroid, $1.2 \%$ in hypothyroidism and $9.9 \%$ in hyperthyroidism. Thyroid ultrasound was performed in $97.5 \%$ of patients. Surgically, gestures performed were divided between the lobo-isthmectomies (43.1\%), subtotal thyroidectomy $(9.8 \%)$, total thyroidectomy $(46.91 \%)$. The postoperative course was uneventful in all patients. The histology was benign in $88.9 \%$ of surgical specimens and found adenocarcinoma in $11.1 \%$. Conclusion: Our study confirms the predominance of female thyroid pathology. The thyroidectomy which is getting better codified occupies an important place in the management. It offers the advantage around the problem of therapeutic non-compliance and also stockouts in our region.
\end{abstract}

\section{Keywords}

Thyroid Disease, Thyroidectomy, Saint Louis, Senegal

\section{Introduction}

Goiter defines an increase in the volume of the thyroid body. The risks associated with surgery for treating thyroid diseases and the problems of adequate hormonal replacement have deterred surgeons from performing total thyroi- 
dectomies [1].

Surgery is currently an important option in the treatment of some thyroid conditions, especially in oncology. It is also the therapeutic choice for large nodules, multi nodular goitre and hyperthyroidism [2] [3].

It has been shown that the complication rates of permanent recurrent laryngeal nerve palsy $(0 \%-1.3 \%)$ and permanent hypoparathyroidism (1\%) following subtotal thyroidectomy are similar to those following total thyroidectomy [1]. In Senegal, the use of surgery for the treatment of thyropathies is frequent because of economic requirements [2].

So we did a retrospective study over a period of 06 years. The main objective was to study the indications and results of thyroidectomies in Saint-Louis.

\section{Materials and Methods}

We conducted a descriptive retrospective study over a period of 06 years. All patients who had consulted for goiter and had thyroidectomy in the department during the study period were included. The paraclinical assessment was clinically oriented and included: thyrotropin dosage, cervical ultrasound and pathological examination of the operative specimen.

The Epi Info 6 computer software was used for data collection and processing.

\section{Results}

1) Epidemiological and clinical data (Table 1).

Table 1. Demographic and clinical characteristics.

\begin{tabular}{ccc}
\hline Age & Number & Percentage \\
\hline $10-29$ & 17 & 20.99 \\
$30-49$ & 44 & 54.34 \\
$50-69$ & 18 & 22.21 \\
70 and over & 2 & 2.46 \\
Sex & & \\
Men & 4 & \\
Women & 77 & \\
Goiter seat & & 56.8 \\
Diffuse & 46 & 42 \\
Lobar & 34 & 1.2 \\
Isthmian & 1 & 98.7 \\
Goiter consistancy & & 1.3 \\
Firm & 80 & 88.9 \\
Hard & 1 & 9.9 \\
Biological signs & & 1.2 \\
Euthyroidism & 72 & \\
Hypothyroidism & 8 & \\
Hyperthyroidism & 1 & \\
\hline
\end{tabular}


Our series consisted of 4 men and 77 women, a sex ratio of 0.05 . The age of our patients was between 11 and 85 years old with an average of 40 years. The most representative age group was between 30 and 49 years old.

The duration of goitre progression in patients was between one and 180 months with an average of 30.2 months.

In our study 46 of the patients had diffuse goiter or $56.8 \%$ of patients; 34 had a lobar location with 20 cases of right lobar goiter (i.e. $24.7 \%$ of patients) and 14 cases of left goiter (17.2\% of patients). One of the patients had isthmic goitre (1.2\%).

Clinical examination in our patients found only 5 cases of compressive goitre, or $6.2 \%$ of patients. The stigmata of compression were represented by dysphagia and dysphonia

2) Paraclinical data.

TSH was dosed in all patients. 88.9\% (72 patient) were found in euthyroid, 9.9\% (8 patients) inhypothyroidism and 1.2\% (1 patient) inhyperthyroidism.

Across the sample, 79 patients underwent cervical ultrasound, representing $97.5 \%$ of patients.

3) Thyroidectomies and operative follow-up.

Of the 81 thyroidectomies performed in our patients, we identified four types of actions. The Table 2 summarizes all the actions taken.

Duration of hospitalizationvaried between 2 and 4 days, with an average of 2.25 days.

The consequences were simple in all the patients, none of them presented complications in the post-operative period.

In our study 81 patients underwent surgery for the thyroid gland and no deaths were recorded.

Of the 81 thyroidectomies performed, only 18 patients underwent histological examination of the operative specimen, i.e. $22.2 \%$. The distribution of the conclusion of histology is shown in Table 3.

\section{Discussion}

In our study the peak frequency is between 30 and 49 years with an average of 40 years. Studies in Africa and elsewhere have returned to an average age of around 40 years [2] [3] [4] [5] [6].

Thyroid pathology has a female predominance supported by the review of [2]

Table 2. Summary of surgical procedures performed.

\begin{tabular}{ccc}
\hline Surgical gesture & Number & Percentage $(\mathrm{n}=81)$ \\
\hline Right lobo-isthmectomy & 22 & $27 \%$ \\
Left lobo-isthmectomy & 13 & $16 \%$ \\
Total thyroidectomy & 38 & $47 \%$ \\
Subtotal thyroidectomy & 8 & $10 \%$ \\
Total & 81 & $100 \%$
\end{tabular}


Table 3. Results of the histology of the operative specimens.

\begin{tabular}{ccc}
\hline Histology & Number & Pourcentage \\
\hline Thyroid adenocarcinoma & 2 & $11 \%$ \\
Thyroid adenoma & 12 & $67 \%$ \\
Thyroiditis of Hashimoto & 4 & $22 \%$ \\
Total & 18 & $100 \%$ \\
\hline
\end{tabular}

[3] [5] [6]. It explains the larger number of women in whom the operative indication is posed. Our study has highlighted this predominance.

Duration of thyroidopathy is long in our patients with an average of 2 and a half years. However, this duration of evolution remains lower than those described in Africa, which varies between 5.8 years and 7 years [2] [3] [4]. We found signs of compression in patients with heteronodular goiter: dysphagia $(3.7 \% \mathrm{n}=3)$, dysphonia $1.2(\% \mathrm{n}=1)$ are the clinical stigmas of this compression. This complication is also found in another study conducted in Dakar, where signs of compression were present in $6.9 \%$ of patients [2].

$88.9 \%$ of our patients were in euthyroidism, this clear predominance of euthyroidism is partly related to the fact that the biological balance was always sought by medical treatment before programming the surgery. However, most of our series consisted of nodular goiters (85.2\%).

In our study, $1.2 \%$ had hypothyroidism while another study in Dakar [2] was about quadriple (5.7\%)

During the study period, 81 thyroid surgeries were performed, and 4 main gestures were performed: left or right lobo-isthmectomy, total and subtotal thyroidectomy.

The surgical procedure depends on the location of the nodules and the appearance of the rest of the parenchyma. The goal is always to remove the pathological areas while leaving in place the healthy parenchyma according to feasibility.

The lobo-isthmectomy is performed in case of nodules occupying the entire lobe, if both lobes are interested with a healthy parenchyma a total thyroidectomy is performed.

In the literature the main indications of nodular goiter were lobo-isthmectomy, subtotal thyroidectomy and total thyroidectomy. The place of choice of lobo-isthmectomy in the management of thyroid pathology, especially if it concerns a part of the gland, makes a broad consensus [7]-[14].

The average length of hospital stay in our series is 2 days. It was significantly more important for Ndour [2] with (3.4 days).

In the West the patient can return to his home on the second day after the procedure as described by Guerrier B. et al. [15].

The follow-up was simple for the 81 thyroidectomies. No patient presented complications in the post operative period. The percentage described in other studies in Senegal is around 7\% [4]. 
Mortality in thyroid surgery is rare. Several series have described zero mortality [2] [14]. The Ndour study [1] noted a mortality of 0.5 .

In our series, 18 patients (22.2\% of the series) had exploitable histology. Dieng [3] had a contribution to histology in $59.3 \%$ of patients in his series. In another study done in Dakar 87.5\% of exploitable histology was found [2].

Histological examination of the operative specimen should be systematic after thyroidectomy. This availability of anatomopathological examination is not yet in the routine of our technical trays but reinforces the quality of care.

\section{Conclusions}

Thyroid pathology is common in Senegal with a predominance of hetero-multinodular goiters.

Thyroid surgery remains a credible alternative in management with convincing results, but the approach must be multidisciplinary.

\section{References}

[1] Efremidou, E.I., Papageorgiou, M.S., Liratzopoulos, N. and Manolas, K.J. (2009) The Efficacy and Safety of Total Thyroidectomy in the Management of Benign Thyroid Disease: A Review of 932 Cases. Canadian Journal of Surgery, 52, 39-44.

[2] Dieng, M., Cissé, O., Ndour, D., Konaté, I., Touré, O., Ka, O., Dia, A., et al. (2010) Indications et résultats des thyroidectomies réalisées au sein d'un service de chirurgie générale. Propos de 402 patients opérés. Revue Africaine de Chirurgie et Spécialités, 4, 24-32

[3] Darre, T., Amegbor, K., Amana, B., Pegbessou, L., et al. (2014) Profil histo épidémiologique des tumeurs du corps thyroide. Médecine d Afrique Noire, 1, 249-251.

[4] Dieng, N.O., Ka, O., Konate, I. and Toure, C. (2006) Traitement chirurgical des hyperthyroidies de la maladie de Basedow et du goitre nodulaire basedowiflé. Revue Afrique de Chirurgie, 9, 38-41.

[5] Keita, M., Diango, D., Traore, C., Kamati, M., et al. (2007) Les goitres bénins en ORL: Aspects épidémiologiques et anatomo cliniques. Journal of Tumor, 18, 16-19.

[6] Makeief, M., Marler, F., Khudjadze, G.R. and Campette, L. (2000) Les goitres plongeants à propos de 212 cas. Annales de Chirurgie, 125, 18-25. https://doi.org/10.1016/S0001-4001(00)00117-3

[7] Bernard, G., Michel, Z., Guy, L. and José, S. (2006) Chirurgie de la thyroïde et de la parathyroïde. Annales de Chirurgie, 41, 27-30.

[8] Bilosi, M., Binquet, C., Goudet, P., Lalanne-Mistrih, M.L., Brun, J.M. and Cougard, P. (2002) La thyroïdectomie subtotale bilatérale de réduction reste-t-elle indiquée dans la maladie de Basedow? Annales de Chirurgie, 127, 115-120. https://doi.org/10.1016/S0003-3944(01)00689-7

[9] Cougard, P., Osmak, L. and Goudet, P. (2005) La thyroïdectomie endoscopique. Journal de Chirurgie, 142, 375-377. https://doi.org/10.1016/S0021-7697(05)80958-5

[10] Atoini, F., Zidane, A. and Traibi, A. (2009) Traitement chirurgical des goitres plongeants: A propos de 27 patients. Journal de Chirurgie Viscérale, 146, 229-231. https://doi.org/10.1016/j.jchir.2009.05.010

[11] Leger, A. (2001) Diagnostic et traitement. Pathologie thyroïdienne. Médecine Science, 45, 1-99. 
[12] Monabeka, H., Peka, J.F., Kibeka, P., Bouenizabida, E. and Nsakalakibangou, N. (2005) La pathologie thyroïdienne au CHU de Brazzaville. Cahiers Santé, 15, 37-40.

[13] Petite, C. and Meier, A.C. (2004) Nodules thyroidiens et goitres: Le traitement chirurgical. Swiss Medical Forum, 4, 1090-1096.

[14] Tresallet, C., Chigot, J.-P. and Menagaux, F. (2005) Comment prévenir la morbidité réccurentielle en chirurgie thyroidienne? Annales de Chirurgie, 9, 150-153.

[15] Guerrier, B., Zanaret, M., Le Clech, G. and Santini, J. (2006) Chirurgie de la thyroide et de la parathyroide edition. Amplifon, 41, 208. 